\title{
İşletme Grupları Ve Sermaye Yapısı İlişkisi
}

\author{
Meltem GÜRÜNLÜ *
}

\section{$\ddot{O Z E T}$}

Dünyada pek çok ülkede var olan işletme gruplarının oluşum ve yaygınlık nedenleri pek çok akademisyenin ilgisini çekmiştir. İşletme gruplarının oluşumunda temel nedenler piyasa kusurları ve bilgi sorunlarını önlemek, piyasa belirsizliklerini azaltmak ve riski çeşitlendirmek olarak sıralanabilir. Bu çalışma, Türkiye'deki firmaların sermaye yapısı seçimlerinin bir işletme grubuna bağlllık nedeni ile farklılaşıp farklılaşmadiğını incelemektedir. Çalışmada Borsa İstanbul'da işlem gören, finansal sektör dişındaki 68 adet şirketin 2008-2016 yllları arasindaki dönemini kapsayan ve toplamda 612 gözlemin yer aldı̆̆ dengeli bir panel veri seti ile çalışılmıştır. Araştırma yöntemi olarak dinamik panel veri analizi yöntemi kullanılmıştır. Genelleştirilmiş momentler yöntemi (GMM) ile tahmin edilen modeldeki sermaye yapısını açıklayıcı değişkenler sermaye yapısı ile ilgili üç önemli teori baz alınarak kullanılmıştır. Bunlar, dengeleme teorisi, gagalama siralaması teorisi ve temsil maliyetleri teorisidir. Çalışmanın başlıca bulgusu işletme grubuna bağlı şirketlerin bağımsız firmalara göre daha fazla kaldıraca sahip olduğudur. Bu bulgu da işletme grupları ve içsel sermaye piyasaları ile ilgili teorileri destekler niteliktedir.

Anahtar Kelimeler: Işletme grupları, sermaye yapısı, sahiplik yapısı, panel data, içsel sermaye piyasaları, gelişen piyasalar.

JEL Sinıflandırmasi: G30, G32, G34, G35.

\section{The Relation Between Business Groups And Capital Structure}

\section{ABSTRACT}

The reasons for the formation and prevalence of business groups in many countries around the world have attracted the interest of many academicians. The main reasons for the formation of business groups can be listed as preventing market imperfections and information problems, reducing market uncertainties and diversifying risks. This study examines how being affiliated to a business group affects the capital structure of companies in Turkey. For this aim, a balanced panel data set for 68 companies from the nonfinancial sector, traded in the Istanbul Stock Exchange, covering a total of 612 observations for the period 2008-2016 (9 years) was constructed. As the research methodology, dynamic panel data analysis method was used. The model was estimated using the GMM (Generalized Method of Moments). The variables explaining the model are based on three important theories of capital structure, namely the trade off theory, the pecking order theory and the agency costs theory. The main finding of the study is that companies affiliated to a business group have more leverage than non-affiliated firms. This finding supports the theories about business groups and internal capital markets.

Keywords: Business groups, capital structure, ownership structure, panel data, internal capital markets, emerging markets.

Jel Classification: G30, G32, G34, G35.

\footnotetext{
* Dr. Öğr. Üyesi Meltem Gürünlü, İstanbul Arel Üniversitesi, Uluslararası Ticaret ve Finans Bölümü
} 


\section{GíRiș}

Bir iş grubu "ortak bir idari veya mali kontrol altında farklı pazarlarda faaliyet gösteren ve üyeleri kişisel, etnik veya ticari geçmiş ilişkileri ile bağlantılı olan bir grup şirkettir. Başka bir deyişle, bir işletme grubu, ortak mülkiyeti paylaşan farklı menfaatlere sahip birkaç şirketin bir araya toplanmasıdır (Gronovetter,1995, Khanna ve Rivkin, 2001 ve Lef 1978). İş grupları, tek bir ailenin çoğunluğa sahibi olduğu (Faccio ve Lang,2002), çapraz ortaklık ve ortak yönetim ile karakterize edilen yapılardır (Khanna ve Palepu, 2000). İşletme grupları hem gelişmiş hem de gelişen ekonomilerde önemli roller oynamaktadır. Örneğin; Japonya, Latin Amerika, Güney Kore, Çin, Tayvan, Hindistan, Almanya, İtalya, Türkiye.

İşletme gruplarının oluşum ve yaygınlık nedenleri pek çok akademisyenin ilgisini çekmiştir. Bu alandaki başlıca çalışmalar Khanna (2000); Guillén (2000) ve Feenstra, Huang ve Hamilton (2003), Khanna ve Rivkin (2006) olarak sıralanabilir. Bu yazarlara göre, İşletme gruplarının oluşumunda temel nedenlerin ilki piyasa kusurları ve bilgi sorunları nedeniyle grupların oluşmasıdır; ikincisi yeni bir iş ortağ 1 aramak yerine, aynı iş ortağıyla birlikte iş yapmak bireysel bir firmanın piyasa belirsizliklerini azaltmaya yardımcı olmaktadır ve son olarak, gruplar sahiplerin riski çeşitlendirme arzusunun bir sonucu olarak veya aile şirketlerinin bir ardılı olma yoluyla oluşturulur.

Finanstaki geleneksel sermaye yapısı teorileri herhangi bir işletme grubu içinde faaliyet göstermeyen bağımsız şirketlere göre tasarlanmıştır. Fakat, bir işletme grubuna bağlı olarak faaliyet gösteren şirketlerin hem işletme grubu içindeki içsel hem de grup dişındaki dışsal sermaye piyasaları kaynaklarına erişimi daha kolay ve bu şekilde erişilen kaynakların kullanımı da daha etkin olabilmektedir (Gertner, Scharfstein ve Stein,1994). Böylelikle, gruba bağlı şirketlerin borç ve öz kaynak yapısı, herhangi gruba bağlı olmayan bağımsız şirketlerinkinden farklı olabilmektedir. Bu makale, Türkiye'deki firmaların sermaye yapısı seçimlerinin bir işletme grubuna bağlılık nedeni ile farklılaşıp farklılaşmadığını incelemektedir.

Çalışmanın başlıca bulgusu işletme grubuna bağlı şirketlerin bağımsız firmalara göre daha fazla kaldıraca sahip olduğudur. Bu bulgu da işletme grupları ve içsel sermaye piyasaları ile ilgili teorileri destekler niteliktedir. Buna göre, işletme grubuna bağlı firmalar bağımsız olan firmalara göre hem içsel hem de dişsal sermaye piyasalarına daha kolay ve masrafsız erişim imkanına sahiptir. Finansal sıkıntı maliyetlerinin daha az oluşu nedeni ile işletme gruplarına bağlı firmalar borcu öz kaynağa tercih etmektedirler. İşletme grupları modern finans teorisinin odağında yer alan bilgi asimetrileri, vergiler ve temsil maliyetlerini kapsayan piyasa kusurlarını azaltmada etkili olabilmektedir. Pek çok gelişmekte olan ekonomide yaygın olan bu tür piyasa kusurları endüstriyel gelişme ve kalkınmanın önünde engel teşkil etmektedirler. Böylelikle, gelişmekte olan ekonomilerde modern finans teorisinin sağladiğ 1 sermaye yapısı ile ilgili standart teoriler, işletme grupları ile ilgili teoriler ile birlikte sentezlenerek ele alınmalidır (Manos, Murinde ve Green, 2007).

\section{LITERATÜR TARAMASI}

Sermaye yapısı ile ilgili üç alternatif teori; dengeleme teorisi (trade off theory), gagalama düzeni teorisi (pecking order theory) ve temsil maliyetleri teorisidir. (agency costs theory). Dengeleme teorisi, firma tarafından mümkün olan en düşük öz sermaye maliyetini 
içeren sermaye bileşiminin seçilerek, optimal sermaye yapısının oluşturulmasını hedefleyen bir yaklaşımdır. (Kraus ve Litzenberg 1973; Myers ,1984). Diğer bir deyişle, bu teori, nakit akım akışına yönelik dış talepleri en aza indirirken aynı zamanda firmanın değerini en yükseğe çıkarabilecek en uygun sermaye yapısının mevcut olduğunu varsaymaktadır. $\mathrm{Bu}$ sermaye yapısı teorisine göre, bir firmanın hedef kaldıracı borcun sağladığı faiz vergi kalkanları ile mali sıkıntının maliyeti arasındaki dengelenme ile belirlenir.

İşletme grubu ile olan bağlantının, sermaye yapısı teorisine çeşitli şekillerde etkileri olabilir. İlk olarak, daha büyük fïrmalar, özellikle de işletme grupları daha çok is çeşitliliği göstermektedir. $\mathrm{Bu}$ da olası geri ödeyememe riskini azaltır ve grubun borç kapasitesini yükseltir. İkincisi, grupların diğer üyeleri çapraz olarak sübvanse etme olasıllı̆g 1 vardır ve grubun itibarını korumak için borç yükümlülüklerini karşılayabilir. Üçüncüsü, borç müzakerelerinde bilgi asimetrisinden kaynaklanan maliyetler işletme grupları arasında daha azdır (Hoshi, Kashyap ve Scharfstein, 1990). Böylece, finansal sıkıntının potansiyel maliyetlerinde azalma, grupların daha fazla borca sahip olmasına izin verir.

Bütün bu faktörler, gruba bağlı firmalar için borç seviyesinin gruba bağlı olmayan firmalara göre daha yüksek olabileceği anlamına gelmektedir. Gruba bağlı firmalar ile bağımsız firmalar arasındaki toplam borç oranındaki farklılıklara ilişkin bazı bulgular, örneğin; Koreli işletme gruplarında bağlı şirketlerin bağımsız şirketlere göre daha fazla kaldıraca sahip olduklarını gösteren (Jung, Kim ve Kim, 2009), Hintli işletme gruplarında bağl1 şirketlerin daha fazla borç alabildiğini gösteren (Manos, Murinde ve Green ,2007), Türkiye'de gruba bağlı firmaların gruba bağlı olmayan firmalardan daha fazla kaynak bulabildiğini gösteren (Gönenç, Kan, Karadağlı 2004;2007).

Myers ve Majlufun (1984) sermaye yapısının gagalama düzeni teorisi (finansman hiyerarşisi kuramı), firmaların, ilk önce içsel birikmiş kârlar, daha sonra borç ve son olarak öz sermaye yoluyla yeni yatırımları finanse etmeyi tercih ettiğini belirtmektedir. Bu teoride bir firma için hedef sermaye yapısı kavramı yoktur. Teori, şirkette içerdekilerin dış yatırımcılardan daha fazla bilgiye sahip olduğu varsayımına dayanmaktadır. Gagalama düzeni teorisi grup üyeliği için de bazı etkilere sahiptir. İlk olarak, içsel sermaye piyasalarının varlığına bağlı olarak, gruba bağlı firmalar iç fonlara daha fazla erişebilmektedir ve bu da diş borç kullanma isteklerini azaltacaktır. İkincisi, grup üyeliği üye firmalar arasındaki bilgi asimetrilerini azaltabilir. Son olarak, bir gruba üye olmak, dış finansmana erişimi artırır, çünkü grubun itibarı bankaların ve diğer alacaklıların algı ve davranışlarını değiştirebilir (Manos, Murinde ve Green, 2007).

Temsil maliyeti teorisi (Jensen ve Meckling, 1976) optimal sermaye yapısının hem borç hem de hisse senedi ihracı maliyetlerini içeren temsil maliyetleri tarafindan belirlendiğini önermektedir. Öz sermaye ile ilgili maliyetler aşağıdakileri içerebilir: (a) hissedarların izleme masrafları (b) yöneticilerin bağlanma giderleri ve (c) yöneticilerin kararının hissedarlardan ayrılması nedeniyle "kalan kayı" (Jensen ve Meckling, 1976). Öte yandan borçlanmak hissedarları ve yöneticileri yüksek riskli fakat yüksek getiri sağlayan projelere yatırım yapmaya teşvik etmektedir ancak bu işletmeye borç verenler için de gerçekleşebilecek bir başarısızlık ihtimalini karşısında riski artıracaktır. Borç sahipleri bunu bekliyorsa, yüksek bir prim talep edebilirler ve bu da borcun maliyetini artıracaktır. Dolayısıyla hem hisse senedi hem de borç temsil maliyetlerine neden olur ve bu nedenle en uygun sermaye yapısı iki maliyet türü arasında bir dengeyi içerir. 
Bir işletme grubuna bağlı firmalarda, temsil çatışmaları büyük bir hissedarın izlemesi ve kontrolü nedeniyle hafifletilebilir. Büyük bir hissedar, yönetici oportünizminin kapsamını azaltabilir, bu da yönetim ile hissedarlar arasındaki temsil çatışmalarının azalmasına neden olur (Shleifer ve Vishny, 1986). Büyük bir hissedar aktif monitör olarak hizmet verirse, yönetim kendi çıkarları doğrultusunda borçlanmaya gidemez. Başka bir deyişle, büyük hissedarlı firmaların borçlanma oranlarının yüksek olması muhtemeldir.

Andersen ve ark. (2003), aile mülkiyetinin daha düşük borç temsil maliyetiyle ilişkili olduğunu ve aile mülkiyetinin, idarecilerin fırsatçılığını azaltmada önemli olduğunu bulmuştur. Buna ek olarak, eğer yönetici gruba bağlı bir firma içinden ise, sahiplik ve kontrol birbirinden ayrılamaz; bunun için hisse sahipleri ve yöneticilerin çıkarları tamamen uyumludur. Bu gibi durumlarda, yöneticilerin sahiplik hisselerinden ötürü, hissedarların zenginliğini azaltan davranışlarda bulunmaya yönelik yönetsel teşvikler azaltılacaktır (Jensen ve Meckling, 1976). Bununla birlikte, Fama ve Jensen (1983) yönetsel hisse sahipliğinin, temsil çatışmaları üzerinde hala olumsuz etkilere sahip olabileceğini iddia etmektedir; çünkü bu fenomen, yönetimin yerini sağlamlaştırmasına yönelik faaliyetlerine yol açabilmektedir.

Yukarıdaki teorik tartışmalar ışı̆̆ında, bu çalışma Türkiye'de gruba bağlı firmalarla, herhangi bir gruba bağlılı̆̆ bulunmayan bağımsız firmaların sermaye yapıları arasındaki farkları ortaya çıkarmaya çalışmaktadır. Sonuç olarak, işletme grupları modern finans teorisinin odağında yer alan bilgi asimetrileri, vergiler ve temsil maliyetlerini kapsayan piyasa kusurlarını azaltmada etkili olabilmektedir. Pek çok gelişmekte olan ekonomide yaygın olan bu tür piyasa kusurları endüstriyel gelişme ve kalkınmanın önünde engel teşkil etmektedirler. Böylelikle, gelişmekte olan ekonomilerde modern finans teorisinin sağladığ 1 sermaye yapısı ile ilgili standart teoriler, işletme grupları ile ilgili teoriler ile birlikte sentezlenerek ele alınmalıdır. (Manos, Murinde ve Green, 2007)

\section{VERI SETİ VE METODOLOJI}

Çalışmada Borsa İstanbul'da işlem gören, finansal sektör dışındaki 68 adet şirketin 2008-2016 yılları arasındaki dönemini kapsayan ve toplamda 612 gözlemin yer aldığı dengeli bir panel veri seti ile çalışılmıştır. Bu şirketlerin 42 tanesi bir gruba bağl1, 26 tanesi ise bağımsız şirketlerden oluşmaktadır. Veriler borsa İstanbul ve kamuoyunu aydınlatma platformundaki finansal tablolar ve şirket raporlarından elde edilmiştir. Dinamik panel veri analizi yöntemi kullanılmıştır. Modeli tahmin etmekte havuzlanmış en küçük kareler yöntemi ve genelleştirilişmiş momentler tahmin yöntemleri kullanılmıştır.

Dinamik panel veri modelleri, bağımlı değişkeni etkileyen faktörler arasına, bağımsız değişken veya değişkenlerin gecikmeli değerlerinin ve ayrıca bağımlı değişkenin gecikmeli değerlerinin de dahil edildiği modellerdir. (Tatoğlu, 2013). Dinamik panel modeli en iyi Arellona ve Bond (1991) tarafindan geliştirilen GMM (Genelleştirilmiş Momentler Metodu) yöntemi ile tahmin edilmektedir. Bunun nedeni bağımlı değișkenin gecikmeli değerinin modelde yer alması ve bununla hata terimleri arasında ilişki olması nedeniyle modelin tahmininin en küçük kareler yöntemi ile mümkün olmamasından kaynaklanmaktadır. Bağımlı değişkenin gecikmeli değerlerinin açıklayıcı değişken olarak kullanılması, denklemde yer alan diğer açıklayıcı değişkenler ile hata terimlerinin korelasyon içerisinde olmasına neden olmaktadır. Bu da en küçük kareler tahmincilerinin sapmalı ve tutarsız olmasına yol açacaktır. Böylelikle dinamik panel verileri içeren model yapısının tahmini için kullanılabilecek en 
uygun tahmin yöntemi Arellano ve Bond (1991) tarafindan önerilen genelleştirilmiş momentler metodudur (GMM).

Firmaların borç düzeyini belirleyen değişkenler literatür taraması kısmında bahsedilen sermaye yapısı teorileri baz alınarak belirlenmiştir.

Çalışmanın genel modeli aşağıdaki şekilde belirlenmektedir.

$\mathrm{KLD}_{\mathrm{it}}=\beta_{0}+\mathrm{f}\left(\mathrm{SYD}_{\mathrm{it}}\right)+\beta_{1} \mathrm{GRUP}_{\mathrm{it}}+\alpha_{\mathrm{i}}+\alpha_{\mathrm{t}}+\varepsilon_{\mathrm{it}}$

$\mathrm{KLD}_{\mathrm{it}}=\beta_{0}+\mathrm{f}(\mathrm{KRL}, \mathrm{MDV}, \mathrm{BYK}, \mathrm{BFR}, \mathrm{BDVK}, \mathrm{SNA}, \ddot{\mathrm{UBZ}})+\beta_{1} \mathrm{GRUP}_{\mathrm{it}}+\alpha_{\mathrm{i}}+\alpha_{\mathrm{t}}+\varepsilon_{\mathrm{it}}$

$\mathrm{KLD}_{\text {it }}$ kaldıracı, SYD it sermaye yapısı değişkenlerini, GRUP ${ }_{\text {it }}$ gruba bağlı olup olmamayı gösteren kukla değişseni, $\alpha_{i}$ firmaya özgü etkileri, $\alpha_{t}$ ise zaman özgü etkileri belirtmekte kullanılmaktadır. Kaldıraç (KLD), defter değerine göre bulunan toplam borcun toplam varlıklara oranıdır. Sermaye yapısı ile ilgili değişkenler karlılık, maddi duran varlık oranı, firma büyüklüğü, büyüme fırsatları, borcun dışındaki diğer vergi kalkanları, serbest nakit akımı, ürünün benzersizliği gibi geleneksel sermaye yapısı değişkenlerinden oluşmaktadır (Prasad, Green ve Murinde, 2001). Modelde kullanılan sermaye yapısı değişkenleri ile ilgili açıklamalar (SYD) aşağıdaki gibidir;

\section{a) Firma Büyüklüğü (BYK)}

Rajan ve Zingales (1995) büyük firmaların yatırımcılara daha fazla bilgi açıkladığını öne sürmektedir. Büyük firmalar daha az asimetrik bilgilendirme problemine sahip olmalar1 nedeni ile daha fazla öz sermayeye ve daha az borca sahip olmaktadırlar. Bunun için gagalama sıralaması teorisinin de ileri sürdüğü gibi firma büyüklüğü kaldıraç ile negatif ilişkilidir. Diğer yanda, dengeleme teorisine göre daha büyük firmalarda çeşitlendirme daha fazla olacağ göre ise firma büyüklüğü ve kaldıraç arasında pozitif ilişki olmalıdır. Firma büyüklüğü satışların büyüklüğü (doğal logaritması) baz alınarak belirlenmektedir.

b) Karlilık (KRL)

Gagalama sıralaması teorisine göre, firma önce içsel kaynaklardan daha sonra dışsal kaynaklardan fonlamayı tercih edecektir. Karlılık oranı yüksek olan firmalar içsel finansman kaynağı bulmayı borca tercih edeceklerdir. Böylelikle karlılık ve kaldıraç arasında negatif bir ilişki vardır (Rajan ve Zingales, 1995). Denge teorisine göre ise daha karlı firmalar vergi kalkanı etkisinden yararlanmak için borcu tercih ederler. Böylelikle, karlık ve kaldıraç arasında pozitif bir ilişki vardır (Boyle ve Eckhold, 1997). Karlılık faiz, vergi ve amortisman öncesi karın toplam varlıklara oranı olarak hesaplanmaktadır.

c) Maddi Duran Varlıklar (MDV)

Temsil Maliyeti teorisine göre, borç verenler ve hissedarlar arasındaki çelişskiler nedeni ile hissedarlar optimal olmayacak şekilde yatırım yapmaya yönelebilirler. Borç verenler maddi duran varlıkları teminat olarak görmek isterler. Böylelikle maddi duran varlıkların toplam varlıklar içindeki payı ile kaldıraç oranı arasında pozitif bir ilişki olmaktadır (Rajan ve Zingales, 1995) 
d) Büyüme Frrsatları (BFR)

Daha fazla büyüme potansiyeli olan firmalar daha fazla fona ihtiyaç duyarlar. Gagalama sıralaması teorisine göre, bu durumda olan firmalar daha dış kaynağa, özellikle de borca ihtiyaç duyarlar. Buna göre, büyüme ve kaldıraç arasında pozitif bir etki olmaktadır. Diğer yanda, büyüme firsatları olan firmalar optimal olmayan bir şekilde yatırım yaparlarsa, borç verenler daha uzun dönemler için borç vermekte daha ihtiyatlı davranacaklardır. Böyle bir durumda, problem kısa dönemli finansman veya hisse senedine çevrilebilen bonolarla çözülebilir (Jensen ve Mecling, 1976, Myers, 1977). Böylelikle, kısa dönemli borç ve büyüme arasında pozitif bir ilişki olmaktadır. Büyüme fırsatlarını ölçmek için toplam satışlardaki yüzde değişimi kullanılmıştır.

\section{e) Serbest Nakit Akımı (SNA)}

Aşırı serbest nakit akımına sahip olan firmalarda yöneticiler, hissedarlara ödeme yapmaktansa bu serbest nakit akımını optimal olmayan yatırım kararları için kullanabilirler (Jensen, 1986). Buna göre serbest nakit akımı ve borç arasında pozitif bir ilişki vardır. Gagalama sıralaması teorisi içsel fonların dışarıdan alınacak borca tercih edileceğini ileri sürmektedir. Böylelikle, Aşırı serbest nakit akımına sahip olan firmaların daha düşük seviyede borca sahip olmaları beklenmektedir. Gagalama siralaması teorisi serbest nakit akımı ve kaldıraç arasında negatif bir ilişi kurmaktadır. Serbest nakit akımı değişkeni vergi ve amortisman öncesi faaliyet karından vergi ve kar paylarının çıkarılması ile bulunmaktadır.

\section{f) Borç Dışındaki Vergi Kalkanları (BDVK)}

Firmalar faizin vergiden düşülmesi ile elde ettikleri vergi kalkanı avantajı nedeni ile borcu tercih ederler. Böylelikle, vergi ve kaldıraç arasında pozitif bir ilişki vardır. Amortisman giderleri de borçla finansmanın sağladığı vergi kalkanı avantajını ikame edebilmektedir. Böylelikle, borç dışı vergi kalkanı amortismanlar ve kaldıraç arasında negatif ilişki beklenmektedir. (De Angelo ve Masulis, 1980). Burada, borç dışı vergi kalkanını ölçmek için toplam amortismanların toplam varlıklar içindeki payı kullanılmaktadır.

\section{g) Ürünün Benzersizliği (ÜBZ)}

Eğer bir firma piyasada benzeri bulunmayan bir ürün üretip satıyorsa, tasfiye durumunda maliyetler artacaktır (Titman ve Wessels, 1988). Dengeleme teorisine göre ürünün benzersiz oluşu ve kaldıraç arasında negatif bir ilişki olacaktır. Ürünün benzersizliğini ölçmek için araştırma ve geliştirme giderlerinin satışlara oranı kullanılmaktadır.

Modelde kullanılan grup kukla değişkeni (GRUP), bir işletme grubuna bağlı olmayı ifade etmektedir ve ana girişimcinin sahip olduğu ortaklık yüzdesi ile ölçülmektedir. Ana girişimcinin şirket üzerinde sahip olduğu pay $\% 51$ 'in üzerinde ise şirket bir işletme grubuna bağlı olarak kabul edilmektedir. Bu şekilde bir işletme grubuna bağlı olan firmalarda ilgili kukla değişken 1, olmayanlarda ise 0 olarak belirtilmektedir.

Tanımlayıcı istatistikler ve korelasyon matrisine aşağıdaki tablolarda yer verilmektedir. 
Tablo 1. Özet İstatistikler

\begin{tabular}{|l|l|l|l|l|}
\hline Değişkenler & Ortalama & St. Sapma & Minimum & Maksimum \\
\hline KLD & 0.35 & 0.78 & 0 & 5.2 \\
\hline KRL & 0.12 & 0,18 & -3.205 & 5.435 \\
\hline MDV & 0.72 & 0.34 & 0.005 & 8.578 \\
\hline BYK & 5.865 & 2.213 & -4.600 & 14.806 \\
\hline BFR & 22.716 & 164.45 & -87.800 & 1784.609 \\
\hline BDVK & 0.024 & 0.16 & 0 & 0.578 \\
\hline SNA & 1338.567 & 9567.45 & 348.98 & 323479,9 \\
\hline ÜBZ & 5.194 & 40.678 & 0 & 1356.58 \\
\hline
\end{tabular}

Tablo 2. Korelasyon Matrisi

\begin{tabular}{|l|l|l|l|l|l|l|l|l|}
\hline & KLD & KRL & MDV & BYK & BFR & BDVK & SNA & ÜBZ \\
\hline KLD & 1.00 & & & & & & & \\
\hline KRL & -0.056 & 1.00 & & & & & & \\
\hline MDV & 0.0215 & 0.075 & 1.00 & & & & & \\
\hline BYK & -0.130 & 0.155 & -0.145 & 1.00 & & & & \\
\hline BFR & -0.005 & 0.024 & -0.012 & -0.025 & 1.00 & & & \\
\hline BDVK & 0.145 & 0.06 & 0.225 & -0.068 & -0.124 & 1.00 & & \\
\hline SNA & -0.015 & 0.052 & 0.017 & 0.036 & 0.0134 & -0.043 & 1.00 & \\
\hline ÜBZ & -0.025 & 0.022 & -0.054 & 0.214 & 0.021 & -0.036 & 0.023 & 1.00 \\
\hline
\end{tabular}

\section{AMPÍRIK ANALIZ}

Çalışmanın modeli önce havuzlanmış en küçük kareler yöntemine göre tahmin edilmiştir. Genel olarak baktığımızda düzeltilmiş $\mathrm{R}^{2}$ değerinin 0.06 gibi çok küçük bir değer olması modelin yeterince açıklayıcı ve uyumlu olmadığını göstermektedir. Firmaya özgü sabit etkiler gözlemlenemediği için, en küçük kareler yöntemi ihmal edilen değişken nedeni ile yanlılık eğilimine yol açmaktadır. Bunun nedeni firmaların sabit etkileri ile açıklayıcı değişkenler arasında korelasyon olmasıdır (Hsiao,1985). Böyle durumlarda, genelleştirilmiş momentler yöntemi ile tahmin daha iyi sonuçlar vermektedir.

Genelleştirmiş momentler yönteminin etkinliği bağımlı değişkenin geciktirilmiş değerlerinin ve diğer açıklayıcı değişkenlerin geçerli araçlar olmasına ve hata terimlerinin seri korelasyon göstermemesine bağlıdır. Bu sorunu aşmak için Arellano ve Bond (1991) üç adet test önermiştir. Birinci test hata terimlerinde birinci mertebeden otokorelasyonun bulunmadığının testidir (AR1). İkinci test hata terimlerinde ikinci mertebeden otokorelasyon bulunmadığının testidir (AR2). Üçüncüsü ise Sarganın aşırı kısıtlamaları belirleme testidir. Bu test araçların geçerliliğini test eder ve asimptotik dağılım varsayımında bulunur.

Modeli genelleştirilmiş momentler yöntemi ile tahmin ettiğimizde, Sargan testinin araçların geçerliliği ile ilgili sıfır hipotezini 1\% anlamlılık seviyesinde reddettiğini görüyoruz. $\mathrm{Bu}$ firmaya özgü etkilerin dışsal olduğunu ifade etmektedir. Birinci ve İkinci mertebeden otokorelasyon testlerinin sonuçları modelin doğru tanımlandığını ve firmalara ait gözlemlenemeyen sabit etkilerin anlamlı düzeylerde olmadığını göstermektedir. İşletme gruplarına bağlılığın kaldıraç oranı üzerine etkilerinin gösterildiği Tablo 3'de ki istatiksel sonuçlar aşağıdaki gibi yorumlanmaktadır. 
Kaldıraç rasyosunun gecikmeli değeri $\left(\mathrm{AKLD}_{\mathrm{i}, \mathrm{t}-1}\right)$ istatiksel olarak anlamlı seviyede (\%1) pozitiftir. Bu da firmaların hedef kaldıraç oranına hızlı şekilde adapte olduklarını ve diğer türlü maliyetlerinin artacağını göstermektedir.

Amortisman, faiz ve vergi öncesi karın toplam varlıklara bölünmesi ile bulunan karlılık oranı (KRL)\%1 anlamlılık seviyesinde negatiftir. Karlılık değişkenin göreceli olarak daha büyük bir negatif tahmin katsayısının olması karlı olan firmaların içsel kaynakları dışsal borçlara tercih ettiği gagalama sıralaması teorisi ile uyum içerisindedir. Bu da yüksek karlılığ olan firmaların daha az borç kullandığını, çünkü daha fazla içsel olarak yaratılmış fona sahip olduğunu göstermektedir.

Firmaların aldıkları borca karşılık gösterdikleri teminat oranını gösteren değişken (MDV) \%1 seviyesinde pozitif tahmin katsayısına sahiptir. $\mathrm{Bu}$ da dengeleme teorisini destekler niteliktedir. Çünkü, borcun kullanılması ile ilgili temsil maliyeti veya iflas maliyeti gibi pek çok maliyet vardır ve maliyetler sabit duran varlıklar gibi teminatlar kullanılarak azalt1labilir.

Firmaların büyüklüğü (BYK) satışların doğal logaritması ile ölçülmektedir ve kaldıraç ile negatif ilişkili bulunulmaktadır. Büyüme Fursatları (BFR) kaldıraç ile anlamlı bir şekilde negatif ilişkilidir. Bu negatif ilişki yüksek büyüme hızına sahip firmaların finansal sıkıntı maliyetlerinin ve borcun temsil maliyetlerinin daha yüksek olduğunu göstermektedir. Borcun maliyetinin yüksek olması nedeni ile yöneticiler borç çıkarmama yoluna gidecekler, bu da düşük kaldıraç oranlarına yol açacaktır.

Borcun dışındaki vergi kalkanları (BDVK) \%1 anlamlılık seviyesinde pozitif etkiye sahiptir. Bu da yüksek oranda borç dışı vergi kalkanına (amortismanlar) sahip şirketlerin borcu daha fazla tercih ettiklerini ve faiz giderlerini vergi kalkanı olarak kullandıklarını göstermektedir. Bu bulgu borç dışındaki vergi kalkanlarının borcun sağladığ 1 vergi kalkanını ikame ettiğini ileri süren dengeleme teorisi ile çelişkilidir.

Ürünün benzersizliği ile ilgili ÜBZ ve serbest nakit akımı ile ilgili SNA değişkenleri ise KLD (kaldıraç) ile anlamlı düzeyde bir ilişki göstermemektedir. Çalışmadaki en önemli değişken ve işletme grubuna bağlı olup olmamayı gösteren GRUP değişkeni ile kaldıraç düzeyi (KLD) arasında \%1 anlamlılık seviyesinde pozitif bir ilişki bulunmaktadır. Bu da bir işletme grubuna bağlı şirketlerin, bağımsız olan şirketlere göre daha fazla borçlanabildiğini göstermektedir. Bunun nedenleri arasında gruba bağlı şirketlerde borcun temsil maliyetinin daha az oluşu hem içsel hem de dışsal sermaye piyasalarına gruba bağlı olmanın getirdiği artan repütasyon nedeni ile daha kolay erişim ve grup içerisinde bilgi asimetrilerinin az oluşu nedeni ile borcun yenilenmesinin ve uzatılmasının daha az maliyetli oluşu gibi nedenler siralanabilir (Hoshi, Kashyap ve Scharfstein (1990). 
Tablo 3. İşletme Grubuna Bağlılığın Kaldıraç Oranına Etkileri

\begin{tabular}{|c|c|c|}
\hline Açıklayıcı Değişkenler & $\begin{array}{l}\text { Model (1) } \\
\text { Havuzlanmış EKK ile tahmin }\end{array}$ & $\begin{array}{l}\text { Model (2) } \\
\text { GMM ile tahmin }\end{array}$ \\
\hline Sabit & $\begin{array}{l}0.282 \\
(0.030)^{* *}\end{array}$ & $\begin{array}{l}-0.002 \\
(0.001)^{*}\end{array}$ \\
\hline $\mathbf{A K L D}_{\mathrm{i}, \mathrm{t}-1}$ & - & $\begin{array}{l}0.122 \\
(0.0004)^{*}\end{array}$ \\
\hline KRL & $\begin{array}{l}-0.265 \\
(0.05)^{* * * *}\end{array}$ & $\begin{array}{l}-0.544 \\
(0.003)^{*}\end{array}$ \\
\hline MDV & $\begin{array}{l}0.373 \\
(0.027)^{\text {** }}\end{array}$ & $\begin{array}{l}0.172 \\
(0.017)^{*}\end{array}$ \\
\hline$\overline{\text { BYK }}$ & $\begin{array}{l}-0.039 \\
(0.005)^{* *}\end{array}$ & $\begin{array}{l}-0.004 \\
(0.009) *\end{array}$ \\
\hline BFR & $\begin{array}{l}-0.00007 \\
(0.00002)^{*}\end{array}$ & $\begin{array}{l}-0.0003 \\
(0.0001)^{*}\end{array}$ \\
\hline BDVK & $\begin{array}{l}0.594 \\
(0.438)\end{array}$ & $\begin{array}{l}1.227 \\
(0.00343)^{*}\end{array}$ \\
\hline SNA & $\begin{array}{l}6.967 \\
(0.2578)\end{array}$ & $\begin{array}{l}7.846 \\
(0.3561)\end{array}$ \\
\hline$\ddot{\mathbf{U B Z}}$ & $\begin{array}{l}0.0001 \\
(0.20)\end{array}$ & $\begin{array}{l}0.0009 \\
(0.125)\end{array}$ \\
\hline Grup & $\begin{array}{l}0.005 \\
(0.019) * *\end{array}$ & $\begin{array}{l}0.05 \\
(0.002)^{*}\end{array}$ \\
\hline Adj. $R^{2}$ & 0.06 & - \\
\hline AR (1) & - & -1.02 \\
\hline AR (2) & - & 1 \\
\hline Sargan Testi & - & $\begin{array}{l}113.76^{*} \\
(27)\end{array}$ \\
\hline
\end{tabular}

\section{SONUÇ}

Bu çalışmada Borsa İstanbul'da kayıtlı, finansal olmayan sektörlere ait 68 şirket için (42 tanesi işletme grubuna bağlı, 26 tanesi bağımsız) bir işletme grubuna bağlı olmanın sermaye yapısına etkileri 2008-2016 yılları (9 y1l) arasındaki şirket verileri dikkate alınarak (toplamda 612 firma-yıl gözlem verisi) incelenmektedir. Kurulan modelin parametreleri hem havuzlanmış en küçük kareler yöntemi hem de genelleştirilmiş momentler yöntemi kullanılarak tahmin edilmiştir. Kullanılan tahmin yöntemleri arasında en sağlamı genelleştirilmiş momentler yöntemi olmaktadır. Çünkü, dinamik panel veri analizinde bağımlı değişkenin gecikmeli değerlerinin açıklayıcı değişken olarak kullanılması, denklemde yer alan diğer açıklayıcı değişkenler ile hata terimlerinin korelasyon içerisinde olmasına neden olmaktadır. Bu da en küçük kareler tahmincilerinin sapmalı ve tutarsız olmasına yol açacaktır.

Genelleştirilmiş momentler metodunda ilgili parametrelerin tahminini yapmak için, hatanın gelecekteki değerlerinin, açıklayıcı değişkenlerin şimdiki değerleri ile korelasyonu olmadığı varsayımı ile moment koşulları oluşturmaktadır (Arellano ve Bond, 1991). Ayrıca optimal moment koşulları için bağımlı değişkenin gecikmeli değerleri ve bağımsız değişkenlerin gecikmeli değerleri kullanılmaktadır. Bundan dolayı söz konusu yöntem, büyük $\mathrm{N}$ ve küçük $\mathrm{T}$ içeren örneklemler için etkin ve tutarlılığı sağlamaktadır. Dolayısıyla, tüm geçerli gecikmeli değişkenlerin dinamik panel veri modellerinde araç değişken olarak 
kullanılması önerilmektedir. Böylece gözlemlenemeyen bireysel etkilerdeki farklılıkları ortadan kaldıran genelleştirilmiş momentler yöntemi tahmin edicileri, bağımlı ve bağımsız değişkenlerin olanaklı tüm gecikmelerini araç değişken olarak kullanır (Arellano ve Bond, 1991). Sonuç olarak, genelleştirilmiş momentler metodu gözlemlenemeyen firmaya özgü etkilerin ve içsellik sorununun kontrolüne olanak sağlar.

Genelleştirilmiş momentler yöntemi ile tahmin edilen modeldeki sermaye yapısını açıklayıcı değişkenler sermaye yapısı ile ilgili üç önemli teori baz alınarak kullanılmıştır. Bunlar, dengeleme teorisi, gagalama siralaması teorisi ve temsil maliyetleri teorisidir. Sermaye yapısı değişkenlerinin kaldıraç üzerine etkileri ile ilgili bulgular bu teorilerle uyumludur. Çalışmanın vurguladığı alanla ilgili en önemli bulgusu işletme grubuna bağlı şirketlerin bağımsız firmalara göre daha fazla kaldıraca sahip olduğudur. Bu bulgu da işletme grupları ve içsel sermaye piyasaları ile ilgili teorileri destekler niteliktedir. Buna göre, işletme grubuna bağlı firmalar bağımsız olan firmalara göre hem içsel hem de dişsal sermaye piyasalarına daha kolay ve masrafsız erişim imkanına sahiptir. Finansal sıkıntı maliyetlerinin daha az oluşu nedeni ile işletme gruplarına bağlı firmalar borcu öz kaynağa tercih etmektedirler

\section{KAYNAKLAR}

Anderson, R.C. - Mansi, S.A. - Reeb, D.M. (2003), "Founding Family Ownership And The Agency Cost of Debt", Journal of Financial Economics, Vol.68, issue.2, pp: 263-285

Arellano, M. - Bond, S.,(1991), "Some Tests Of Specifications For Panel Data: Monte Carlo Evidence And An Application To Employment Equations", Review of Economic Studies, Vol.58, pp:277-297.

Boyle, G.W. - Eckhold, K.R (1997), "Capital Structure Choice And Financial Market Liberalization: Evidence From New Zealand", Applied Financial Economics, Volume 7, Issue 4, pp:427-437

Faccio, M, - Lang, L.(2002), "The Ultimate Ownership Of Western European Corporations", Journal of Financial Economics, Vol.65, pp: 365-395.

Fama, E. - Jensen, M.C.(1983), "Separation of Ownership And Control”, .Journal of Law and Economics, Vol.26, pp: 301-325.

Feenstra, R.C. - Huang, D.S ve Hamilton, G.G. (2003), “A Market Power Based Model Of Business Groups”, Journal of Economic Behavior and Organization, Vol. 51, pp: 459485

Galai, D. - Masulis, R.(1976), “The Option Pricing Model And The Risk Factor Of Stock”, Journal of Financial Economics, Vol. 3, issue 1-2, pp: 53-81

Gertner, R.H.,Scharfstein - D.S, Stein, C.S. (1994), "Internal versus external capital markets", NBER Working Paper Series, Working Paper No.4776

Gonenc, H.- Kan, O. - Karadagli, H. (2007), "Business Groups And İnternal Capital Markets", Emerging Markets Finance and Trade, Vol.43, No.2, pp: 63-81 
Gonenc, H.- Kan, O. - Karadagli (2004), "Corporate Diversification And İnternal Capital Markets: Evidence From The Turkish Business Groups”, Basel Meetings Paper, EFMA 2004, https://papers.ssrn.com/sol3/papers.cfm?abstract_id=500163

Gronovetter, M. (1995), “Coase Revisited: Business Groups İn The Modern Economy”, Industrial and Corporate Change, Vol.4, Issue.1, pp:93-130, https://doi.org/10.1093/icc/4.1.93

Guillén M.F. (2000), "Business Groups In Emerging Economies: A Resource Based View”, Academy of Management Journal, Vol.43, pp: 362-380

Hsiao, C.(1985), "Benefits and Limitations Of Panel Data", Economic Review, Vol.46, issue.4, pp:1251-1271

Hoshi, T. - Kashyap, A. - Scharfstein, D. (1990), "The Role Of Banks in Reducing The Costs Of Financial Distress in Japan”, Journal of Financial Economics, Vol.27, issue.1,pp: $67-88$

Jensen, M. - Meckling, W. (1976), "Theory of The Firm: Managerial Behaviour, Agency Costs And Capital Structure”, Journal of Financial Economics, Vol.3,pp: 305-360

Jensen M. (1986), “Agency Costs Of Free Cash Flow, Corporate Finance And Takeovers”, American Economic Review, Vol. 76, No. 2,pp. 323-329

Khanna T. - Palepu K. (2000), "The future Of Business Groups in Emerging Markets: Long Run Evidence From Chile”, Academy of Management Journal, Vol., pp: 268-285.

Khanna T, Rivkin J W. (2001), "Estimating The Performance Effects Of Business Groups İn Emerging Markets”, Strategic Management Journal, Vol.22, pp: 45-74,

Khanna, T. - Rivkin,J W. (2006), "Interorganizational Ties And Business Groups Boundaries: Evidence From An Emerging Economy”, Organization Science, Vol.17, Issue.3, pp:333-352

Khanna T.(2000), "Business Groups And Social Welfare in Emerging Markets: Existing Evidence And Unanswered Questions", European Economic Review, Vol.44,pp: 748761.

Kraus, A. - Litzenberger, R. (1973), "A State-Preference Model Of Optimal Financial Leverage”, The Journal of Finance, Vol.28,No.4, pp.911-922

Leff, N. (1978), "Industrial organization and entrepreneurship in the developing countries: The economic groups", Economic Development and Cultural Change ,Vol.26, pp: 661-675

Manos, R.- Murinde, V. - Green, C.J. (2007), "Leverage and Business Groups: Evidence From Indian Firms”, Journal of Economics and Business, Vol.59, pp: 443-465 
Myers, S.C. (1984), “The Capital Structure Puzzle”, Journal of Finance, Vol.39, issue.3, pp:575-592

Myers,S. - Majlup, F.(1984), "Corporate Financing And İnvestment Decisions When Firms Have İnformation That İnvestors Do Not Have”, Journal of Financial Economics, Vol. 13, pp:187-221

Myers, S. (1977), "Determinants of Corporate Borrowing”, Journal of Financial Economics, Volume 5, Issue 2, pp: 147-175

Prasad, S.- Green, C.J - Murinde, V. (2001), “Company Financing, Capital Structure And Ownership: A Survey And İmplications For Developing Economies”, Loughborough University Economics Research Paper, http://dspace.lboro.ac.uk

Rajan, R. - Zingales, L. (1995), "What Do We Know About Capital Structure? Some Evidence From İnternational Data”, Journal of Finance, Vol. 50 pp: 1421-1460.

Shleifer, A. - Vishny, R.W. (1986), "Large Shareholders And Corporate Control”, Journal of Political Economy, Vol.94, issue.3, pp:461-488.

Tatoğlu, Y.F. (2013), İleri Panel Veri Analizi, Beta Yayınları, İstanbul

Titman S. - Wessels R. (1988), “The Determinants Of Capital Structure Choice”, Journal of Finance, Vol. 43, No. 1, pp. 1-19. 